\title{
PENGUKURAN KINERJA SUPPLY CHAIN MENGGUNAKAN SUPPLY CHAIN OPERATION REFERENCES (SCOR) DI PT. RAVANA JAYA
}

\author{
Samrotul Fikriyah $^{(1)}$, Eko Budi Leksono ${ }^{(2)}$, Dzakiyah Widyaningrum ${ }^{(3)}$ \\ Program Studi Teknik Industri, Universitas Muhammadiyah Gresik \\ Email : rotu15207@gmail.com
}

\begin{abstract}
ABSTRAK
PT. Ravana Jaya merupakan perusahaan yang bergerak dibidang general contractor. Perusahaan yang menerapkan system make to order ini memproduksi berbagai macam olahan baja. Dalam menjalankan aktivitas rantai pasoknya, PT. Ravana Jaya sering mengalami masalah. Pada proses pengadaan, perusahaan ini sering mengalami keterlambatan raw material sehingga berpengaruh pada pada keterlambatan penyelesaian order sesuai dengan jadwal yang telah ditentukan. Selain itu juga belum adanya indikator-indikator penilaian kinerja rantai pasok yang disajikan dalam Key Performance Indicator (KPI) di PT. Ravana Jaya. Oleh karena itu, penelitian ini dilakukan untuk merancang system pengukuran kinerja supply chain menggunakan Supply Chain Opertion References (SCOR).

Dalam penelitian ini dibahas mengenai pengukuran kinerja supply chain menggunakan Supply Chain Operation Referece (SCOR). Pengukuran dilakukan berdasarkan 5 proses inti (plan, source, make, deliver, dan return), dan beberapa dimensi (reliability,responsiveness, flexibility, coet, dan Asset). Beberapa dimensi tersebut akan didekomposisi dalam beberapa Key Performance Indikator (KPI). Selain itu juga dilakukan pembobotan tiap proses inti, dimensi dan KPI dengan menggunakan Analytical Hierarchy Process. Sedangakan normalisasi snorm de bour digunakanuntuk menyamakan nilai KPI.

Pengukuran kinerja supply chain di PT. Ravana Jaya ini diperoleh 24 KPI. Pegukuran kinerja dilakukan pada project yang ditangani PT. Ravana Jaya pada tahun 2018 dengan total 4 project. Adapun nilai kinerja supply chain perusahaan di tahun 2018 pada project 1 adalah 61,91 (average), project 2 sebesar 61,21 (average), project 3 sebesar 54,09 (average), dan pada project 4 sebesar 75,62 (good).
\end{abstract}

Kata Kunci : Pengukuran Kinerja, Supply Chain Operation References (SCOR), Analytical Hierarchy Process (AHP), Snorm De Bour. 


\section{PENDAHULUAN}

Pengukuran kinerja supply chain merupakan sistem pengukuran kinerja yang bertujuan untuk membantu memantau jalannya aplikasi Supply Chain Management (SCM) di perusahaan agar berjalan dengan baik, efisien, dan efektif. Dengan adanya pengukuran kinerja supply chain, perusahaan dapat mengontrol kinerja perusahaan secara langsung maupun tidak langsung serta perusahaan dapat mengetahui tingkat kinerja perusahaan saat ini, apakah tujuan yang ditetapkan tercapai atau tidak (Vanany, 2009). Salah satu model pengukuran kinerja supply chain adalah Supply Chain Operation References (SCOR). Penerapan SCOR model pada supply chain management menyediakan pengamatan dan pengukuran proses supply chain secara menyeluruh. SCOR model dapat mengukur kinerja secara obyektif dengan berdasarkan data yang ada serta dapat mengidentifikasi dimana perbaikan perlu dilakukan guna menciptakan keunggulan bersaing (Pujawan \& Mahendrawathi, 2010).

PT. Ravana Jaya merupakan perusahaan dengan system make to order yang bergerak dibidang general contractor. PT. Ravana Jaya memiliki jaringan rantai pasok mulai dari supplier, PT. Ravana Jaya, dan langsung kepada Konsumen. Dalam menjalankan aktivitas rantai pasoknya, PT. Ravana Jaya sering mengalami masalah mulai pada proses pengadaan, produksi hingga pengiriman produk ke tangan konsumen. Pada proses pengadaan, perusahaan ini sering mengalami keterlambatan raw material sehingga berpengaruh pada keterlambatan waktu proses produksi yang berujung pada keterlambatan penyelesaian order sesuai dengan jadwal yang telah ditentukan serta terlambatnya pula proses pengiriman. Berikut adalah data keterlambatan pengiriman raw material oleh supplier dan data keterlambatan pengiriman produk ke konsumen :

Tabel 1. Data Keterlambatan Pengiriman Raw Material Oleh Supplier

\begin{tabular}{|l|c|c|c|}
\hline \multicolumn{1}{|c|}{ Supplier } & $\mathbf{1}$ & $\mathbf{2}$ & $\mathbf{3}$ \\
\hline $\begin{array}{l}\text { November } \\
2017\end{array}$ & 2 hari & 1 hari & - \\
\hline $\begin{array}{l}\text { Desember } \\
2017\end{array}$ & - & - & 2 hari \\
\hline Januari 2018 & - & - & - \\
\hline Februari 2018 & - & - & - \\
\hline Maret 2018 & 1 hari & - & 1 hari \\
\hline April 2018 & 1 hari & - & 1 hari \\
\hline Mei 2018 & 2 hari & - & - \\
\hline Juni 2018 & 2 hari & - & - \\
\hline Juy 2018 & - & - & 1 hari \\
\hline Agustus 2018 & - & - & 1 hari \\
\hline $\begin{array}{l}\text { September } \\
\text { 2018 }\end{array}$ & 2 hari & - & - \\
\hline Oktober 2018 & - & - & - \\
\hline
\end{tabular}

Sumber : PT. Ravana Jaya

Tabel 2. Data Keterlambatan Pengiriman Produk ke Konsumen

\begin{tabular}{|c|c|c|c|c|c|}
\hline No & $\begin{array}{c}\text { Nama } \\
\text { Project }\end{array}$ & $\begin{array}{c}\text { Nama } \\
\text { Konsumen }\end{array}$ & Periode & $\begin{array}{c}\text { Schedule } \\
\text { Pengiriman }\end{array}$ & $\begin{array}{c}\text { Actual } \\
\text { Pengiriman }\end{array}$ \\
\hline \multirow[t]{2}{*}{1} & \multirow{2}{*}{$\begin{array}{c}\text { Work Shop } \\
\text { PT indo } \\
\text { Pipe }\end{array}$} & \multirow{2}{*}{$\begin{array}{c}\text { PT } \\
\text { Ardinawa }\end{array}$} & \multirow{2}{*}{$\begin{array}{l}\text { Nov - } \\
\text { Des }\end{array}$} & 5 Des 2017 & 5 Des 2017 \\
\hline & & & & $\begin{array}{c}17 \text { Des } \\
2017\end{array}$ & $\begin{array}{c}20 \text { Des } \\
2017\end{array}$ \\
\hline \multirow[t]{2}{*}{2} & \multirow{2}{*}{$\begin{array}{c}\text { Pengolahan } \\
\text { Kelapa } \\
\text { Sawit }\end{array}$} & \multirow[t]{2}{*}{ PT Pilaren } & \multirow[t]{2}{*}{$\begin{array}{l}\text { Jan- } \\
\text { Mar }\end{array}$} & $\begin{array}{c}25 \mathrm{feb} \\
2018\end{array}$ & $\begin{array}{c}25 \text { feb } \\
2018\end{array}$ \\
\hline & & & & $\begin{array}{c}15 \text { Maret } \\
2018\end{array}$ & $\begin{array}{c}15 \text { Mar } \\
2018\end{array}$ \\
\hline \multirow[t]{2}{*}{3} & \multirow[t]{2}{*}{$\begin{array}{l}\text { Pagar } \\
\text { Pabrik }\end{array}$} & \multirow[t]{2}{*}{$\begin{array}{c}\text { PT } \\
\text { Swadaya }\end{array}$} & \multirow[t]{2}{*}{ Apr-Jul } & $\begin{array}{l}15 \text { jun } \\
2018\end{array}$ & $\begin{array}{c}17 \text { juni } \\
2018\end{array}$ \\
\hline & & & & 20 jul 2018 & 20 jul 2018 \\
\hline \multirow[t]{2}{*}{4} & \multirow[t]{2}{*}{ Jembatan } & \multirow[t]{2}{*}{ PT KMS } & \multirow{2}{*}{$\begin{array}{l}\text { Ags- } \\
\text { Spt }\end{array}$} & 5 sept 2018 & 5 sept 2018 \\
\hline & & & & $\begin{array}{c}25 \text { sept } \\
2018\end{array}$ & $\begin{array}{c}25 \text { sept } \\
2018\end{array}$ \\
\hline 5 & $\begin{array}{l}\text { Rumah } \\
\text { Pompa }\end{array}$ & $\begin{array}{c}\text { PT } \\
\text { Wilmar }\end{array}$ & $\begin{array}{l}\text { Spt- } \\
\text { Okt }\end{array}$ & $\begin{array}{c}20 \mathrm{okt} \\
2018\end{array}$ & $\begin{array}{c}26 \text { okt } \\
2018\end{array}$ \\
\hline
\end{tabular}

Sumber : PT. Ravana Jaya

Untuk dapat tetap memenuhi schedule pengiriman yang telah ditetapkan 
konsumen, maka perusahaan akan menambah waktu kerja bagi pekerja agar dapat menyelesaikan proses produksi sesuai dengan waktu yang telah ditentukan sebelumya. Penambahan waktu kerja bagi pekerja mengakibatkan perusahaan harus mengeluarkan biaya tambahan untuk biaya tenaga kerja, hal tersebut dapat merugikan perusahaan. Dan jika terjadi keterlambatan produk jadi dari PT. Ravana Jaya ke tangan konsumennya, dapat menyebabkan PT. Ravana Jaya harus membayar denda dengan nilai $0,01 \%$ dari nilai kontrak/hari. Apabila denda sudah sampai pada 5\% dari nilai kontrak makan proyek tersebut akan diambil alih oleh perusahaan lain. Hal tersebut akan sangat merugikan perusahaan. Selain itu juga belum adanya indikator-indikator penilaian kinerja rantai pasok yang disajikan dalam Key Performance Indicator (KPI) di PT. Ravana Jaya sehingga belum ada tolak ukur untuk mengevaluasi kinerja rantai pasok perusahaan. Agar suatu pengukuran kinerja dapat dilaksanakan dengan tepat, sebuah perusahaan perlu menetapkan indicator kinerja yang relevan dengan visi-misi-rencana strategis perusahaan (Soemohadiwidjojo, 2015).

Oleh karena itu, penelitian ini dilakukan untuk mengidentifikasi Key Performance Indicator (KPI) yang sesuai dalam pengukuran kinerja supply chain di PT. Ravana Jaya dan untuk mengetahui kinerja supply chain di PT. Ravana Jaya apabila diukur menggunakan Supply Chain Operation References (SCOR).

\section{TINJAUAN PUSTAKA}

\subsection{Pengukuran Kinerja Supply Chain}

Pengukuran kinerja merupakan salah satu elemen kunci dalam supply chain management yang efektif
(Tarasewicz, 2016). Supply chain adalah jaringan perusahaan-perusahaan yang secara bersama-sama bekerja untuk menciptakan dan menghantarkan barang suatu produk ke tangan pemakai akhir (Pujawan \& Mahendrawathi, 2010). Pendekatan proses dalam merancang sistem pengukuran kinerja supply chain memungkinkan untuk mengidentifikasi masalah pada suatu proses sehingga dapat mengambil tindakan perbaikan sebelum masalah tersebut menjadi luas.

\subsection{Supply Chain Operation References (SCOR)}

Menurut Pujawan dan Mahendrawathi (2010), SCOR (Supply Chain Operation Reference) adalah suatu model acuan dari operasi supply chain yang berdasarkan proses. SCOR mampu memetakan bagian -bagian dari supply chain. SCOR membagi prosesproses supply chain menjadi 5 proses inti yaitu plan, source, make, deliver, dan return. SCOR model menyediakan kerangka kerja standar untuk komunikasi yang mudah dan itu merupakan alat yang berguna untuk manajemen puncak perusahaan dalam mencapai kinerja yang diinginkan dengan merancang dan mengkonfigurasi ulang supply chain. Menurut Pujawan \& Mahendrawathi (2010) SCOR memilik tiga hirarki proses. Tiga hirarki tersebut menunjukkan bahwa SCOR melakukan dekomposisi proses yang umum ke yang detail. Tiga hal tersebut adalah:

1. Level 1 adalah level tertinggi yang memberikan definisi umum dari 5 proses diatas (plan, source, make, deliver, dan return).

2. Level 2 dikatakan sebagai configuration level dimana supply chain perusahaan bisa dikonfigurasi berdasarkan 30 proses inti. Perusahaan bisa 
membentuk konfuigurasi saat ini maupun yang diinginkan.

3. Level 3 dinamakan proses element level, mengandung definisi elemen proses, input, output, metrik masing-masing elemen proses serta referensi (benchmark dan best practice).

\subsection{Key Performance Indicator (KPI)}

Menurut Parmenter (2010), Key Performance Indicator atau biasa disingkat dengan KPI merupakan satu set ukuran kinerja yang berfokus pada aspek-aspek kinerja organisasi yang paling penting bagi keberhasilan dan keberlangsungan organisasi saat ini dan masa mendatang. KPI adalah suatu tolak ukur yang biasa digunakan perusahaan untuk mengukur kinerja dan membandingkan antara kinerja satu dengan lainnya (Wigati. dkk, 2017). Sehingga dengan pengukuran KPI, diharapkan dapat mengetahui kemampuan kinerja perusahaan apakah sudah mencapai target yang telah ditepkan atau belum dan juga diharapkan dapat memberikan evaluasi serta perbaikan kinerja.

\subsection{Snorm (Normalisasi)}

Menurut Wigati, dkk. (2017) Normalisasi adalah teknik untuk mengatur data dengan tujuan agar dapat menghilangkan kerangkapan data, dapat mengurangi kompleksitas dan mempermudah untuk memodifikasi data. Pada penelitian ini dilakukan normalisasi dengan normalisasi snorm dikarenakan setiap indikator memiliki nilai dan skala yang berbeda - beda. Adapun rumus normalisasi snorm adalah sebagai berikut :

$$
\begin{aligned}
& \text { Larger is Bettter : } \\
& \text { Snorm }=\left(\frac{(\text { Si-Smin })}{\text { Smax }- \text { Smin }} \times 100\right)
\end{aligned}
$$

\section{Lower is Bettter:}

$$
\text { Snorm }=\left(\frac{(\text { Smax }-S i)}{\text { Smax }- \text { Smin }} \times 100\right) \ldots
$$

\section{Dimana :}

$\mathrm{Si}=$ Nilai indikator aktual yang berhasil dicapai

Smin = Nilai pencapaian performansi terburuk dari indikator kinerja

Smax = Nilai pencapaian performansi terbaik dari indikator kinerja

Pada pengukuran ini, setiap bobot indikator dikonversikan ke dalam interval tertentu yaitu 0 sampai 100 . Nol (0) diartikan paling buruk dan seratus (100) paling baik. Dengan demikian parameter dari setiap indikator adalah sama, selanjutnya didapatkan suatu hasil yang dapat dianalisa. Untuk dapat mengetahui kinerja rantai pasok secara keseluruhan dan terpadu, maka penting untuk mengetahui indeks kinerja dari masingmasing KPI, yang dibuktikan dengan hasil pekalian antara nilai skor dari KPI dengan bobot tiap KPI (Vanany, dkk., 2005).

Tabel 3. Sistem Monitoring Indikator Performansi

\begin{tabular}{|c|c|}
\hline $\begin{array}{c}\text { Sistem } \\
\text { Monitoring }\end{array}$ & $\begin{array}{c}\text { Indikator } \\
\text { Performansi }\end{array}$ \\
\hline$<40$ & Poor \\
\hline $40-50$ & Marginal \\
\hline $50-70$ & Average \\
\hline $70-90$ & Good \\
\hline$>\quad 90$ & Exellent \\
\hline
\end{tabular}

\subsection{Analytical Hierarchy Process \\ (AHP)}

Analytical Hierarchy Process (AHP) merupakan suatu model pendukung keputusan yang dikembangkan oleh Thomas L. Saaty. Model pendukung keputusan ini akan menguraikan masalah multi factor atau multi criteria 
yang kompleks menjadi suatu hirarki. Analitycal Hierarchy Process (AHP) adalah metode untuk memecahkan suatu situasi yang komplek tidak terstruktur kedalam beberapa komponen dalam susunan hirarki, dengan memberi nilai subyektif tentang pentingnya setiap variable secara relative, dan menetapkan variable mana yang memiliki prioritas paling tinggi guna mempengaruhi hasil pada situasi tersebut (Saaty, 1993).

\section{METODOLOGI Penelitian}

Kuesioner yang digunakan pada penelitian ini terdiri dari 3 kuesioner, yaitu kuesioner validitas KPI, kuesioner penentuan bobot, dan kuesioner pennetuan skor. Kuesioner validitas KPIdigunakan untuk beberapa KPI yang digunakandalam pengukuran kinerja supply chain yang dibutuhkan oleh perusahaan. Kuesioner pengisian bobot ini hanya diisi oleh 3 orang yang dianggap expert yang terdiri dari supplier PT. Ravana Jaya, Direktur PT. Ravana Jaya, dan konsumen PT. Ravana Jaya. KPI dinyatakan valid apabila 2 atau lebih responden setuju dengan KPI tersebut sedangkan jika hanya 1 orang, maka KPI dianggap tidak valid.

Kuesioner yang kedua adalah kuesioner perbandingan berpasangan. Kuesioner ini digunakan untuk menentukan bobot tiap KPI, dimensi, dan proses inti. Kuesioner pengisian bobot ini hanya diisi oleh 3 orang yang dianggap expert, karena nantinya akan diolah menggunakan metode AHP. Kuesioner yang ketiga adalah penentuan skorberdasarkan data operasional perusahaan pada setiap proyek. Selanjutnya skor tersebt akan dinormalisasikan dengan metode Snorm de Boer. Normalisasi ini digunakan untuk menyamakan parameter sehingga dapat menentukan skor sebenarnya dari setiap KPI. Langkah selanjutnya dalah menentukan skor kinerja perusahaan, yaitu dengan mengkalikan skor dengan bobot pada tiap KPI. Kemudian dari setiap indicator tersebut akan dimonitoring menggunakan tabel monitoring indicator kinerja. Berikut merupakan diagram alir metode penelitian yang digunakan :

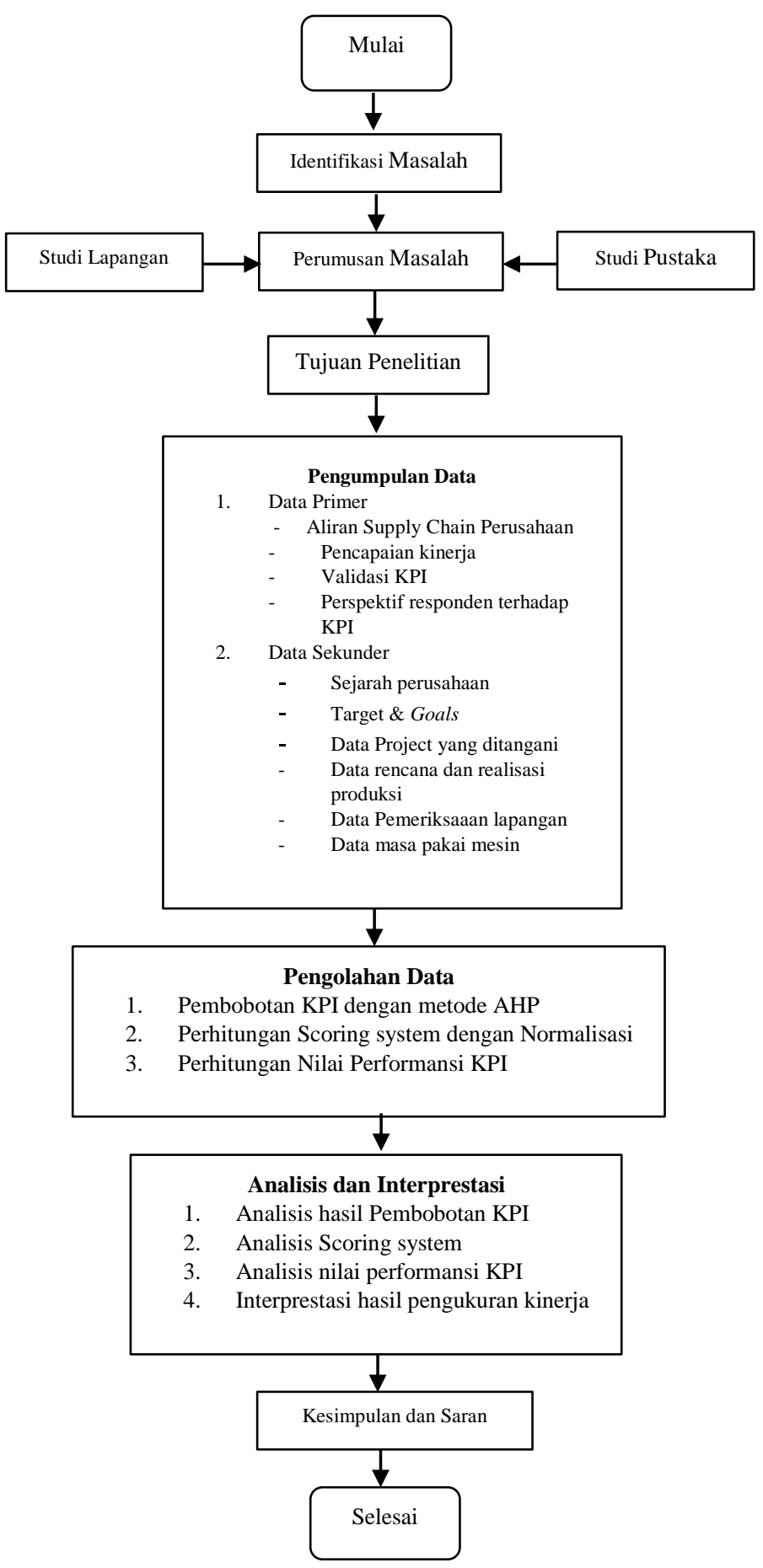


Gambar 1. Diagram Alir Metodologi Penelitian perusahaan untuk dilakukan verifikasi kebutuhan produksi dengan keuangan perusahaan. Apabilasesuai maka selanjutnya pihak accounting akan melakukan pembayaran ke supplier

\section{HASIL DAN PEMBAHASAN \\ 4.1 Aliran Supply Chain \\ Perusahaan}

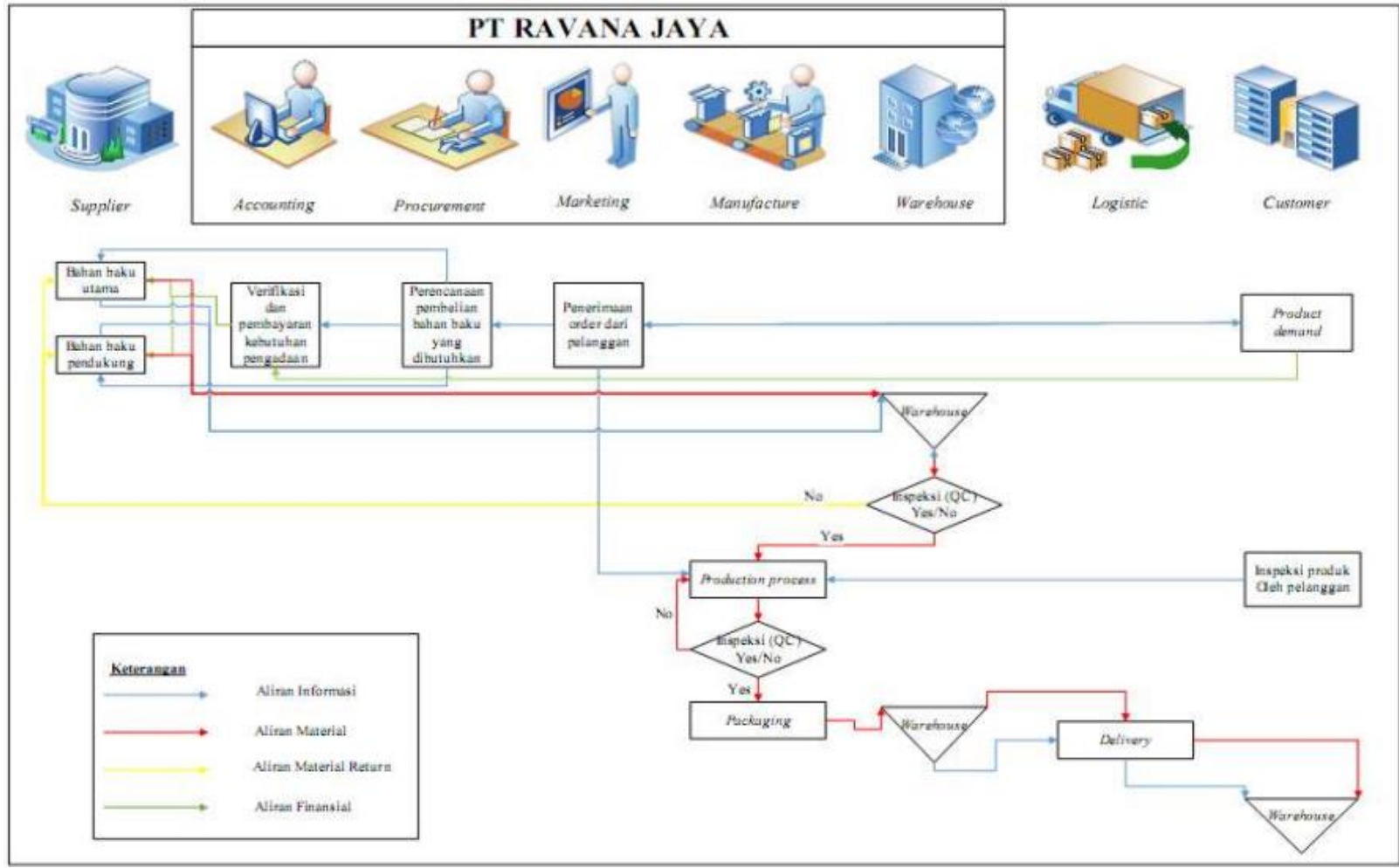

Gambar 2. Aliran Supply Chain PT. Ravana Jaya

Dari gambar tersebut dapat diketahui bahwa aliran informasi (anak panah biru) terjadi saat adanya pesanan dari konsumen yang diterima oleh bagian marketing dan dilanjutkan ke bagian procurement untuk melakukan perencanaan pembelian bahan baku utama dan bahan baku pendukung yang dibutuhkan untuk membuat produk dalam Material Requirement List (MRL) yang sesuai dengan sketsa atau gambar yang telah diberikan oleh pihak konsumen dan disetujui oleh pihak perusahaan. Yang selanjutnya diteruskan ke bagian accounting (anak panah hijau/aliran finansial) dan pihak procurement akan mengirimkan MRL ke supplier untuk dilakukan pengiriman material sesuai kebutuhan perusahaan. Bagian procurement juga akan memberikan informasi kepada pihak produksi mengenai produk yang akan dibuat

Pada sisi supplier, setelah diterimanya Purchase Order (PO) dari perusahaan, selanjutnya supplier akan mengirimkan bahan baku atau material (anak panah merah) yang telah di pesan oleh perusahaan sesuai dengan tanggal kontrak yang ditentukan. Pengiriman 
material yang dilakukan oleh supplier akan di terima oleh perusahaan melalui bagian warehouse perusahaan yang selanjutnya akan dilakukan pengecekan oleh Quality Control (QC).

Pada saat pengecekan QC akan ditentukan apakah bahan baku lolos pengecekan QC atau tidak. Apabila bahan baku telah lolos pengecekan, maka selanjutnya bahan baku akan diteruskan ke bagian produksi untuk dilakukan pengolahan. Dan jika bahan baku tidak lolos pengecekan atau tidak memenuhi standar perusahan, maka bahan baku tersebut akan dikembalikan ke supplier (anak panah kuning).

Di lini manufaktur pada proses produksi, akan dilakukan pengolahan bahan baku menjadi produk jadi yang siap dikirimkan ke pelanggan. Produk yang dihasilkan akan dilakukan pengecekan oleh QC serta customer terlebih dahulu untuk ditentukan apakah produk layak untuk diteruskan ke proses selanjutnya atau tidak. Jika produk lolos pengecekan dan dinyatakan layak, maka produk akan di kemas (Packaging) dan selanjutnya akan di simpan di gudang sebelum dilakukan pengiriman ke pelanggan. Jika produk dinyatakan tidak sesuai, maka produk akan dikembalikan ke proses produksi untuk dilakukan perbaikan atau pengerjaan ulang. Pada lini logistic, perusahaan menggunakan jasa pihak ketiga untuk melakukan pengiriman produk ke pelanggan.

\subsection{Validasi Key Performance Indicator}

Key Performance Indicator yang digunakan pada penelitian ini didapatkan dari beberapa penelitian terdahulu. Dari 28 KPI yang telah didapatkan dari penelitian terdahulu, terdapat $24 \mathrm{KPI}$ valid. $24 \mathrm{KPI}$ ini terdiri dari 5 KPI dari proses plan, 6 KPI dari proses source, 6 KPI dari proses make,
5 KPI dari proses deliver, dan 2 KPI dari proses return. KPI yang divalidasi dapat dilihat pada tabel 4 .

Tabel 4. Key Performance Indicator yang telah tervalidasi

\begin{tabular}{|c|c|c|c|}
\hline $\begin{array}{c}\text { Proses } \\
\text { Inti }\end{array}$ & $\begin{array}{l}\text { Dim- } \\
\text { ensi }\end{array}$ & KPI & $\begin{array}{c}\text { Satu- } \\
\text { an }\end{array}$ \\
\hline \multirow{5}{*}{ Plan } & \multirow{2}{*}{$\begin{array}{l}\text { Relia- } \\
\text { bility }\end{array}$} & $\begin{array}{l}\text { Akurasi perkiraan } \\
\text { jumlah bahan baku }\end{array}$ & $\%$ \\
\hline & & $\begin{array}{l}\text { Kehandalan } \\
\text { karyawan }\end{array}$ & $\%$ \\
\hline & $\begin{array}{l}\text { Respo- } \\
\text { nsive- } \\
\text { ness }\end{array}$ & $\begin{array}{l}\text { Kecepatan dalam } \\
\text { menanggapi } \\
\text { perubahan } \\
\text { permintaan jumlah } \\
\text { bahan baku }\end{array}$ & Jam \\
\hline & \multirow[b]{2}{*}{$\begin{array}{l}\text { Flexi- } \\
\text { bility }\end{array}$} & $\begin{array}{l}\text { Fleksibilitas } \\
\text { penjadwalan } \\
\text { Produksi }\end{array}$ & $\%$ \\
\hline & & $\begin{array}{l}\text { Fleksibilitas dalam } \\
\text { memenuhi jumlah } \\
\text { permintaan } \\
\text { pelanggan }\end{array}$ & $\%$ \\
\hline \multirow{6}{*}{ Source } & \multirow{2}{*}{$\begin{array}{l}\text { Relia- } \\
\text { bility }\end{array}$} & $\begin{array}{l}\text { Persentase } \\
\text { kecacatan bahan } \\
\text { baku }\end{array}$ & $\%$ \\
\hline & & $\begin{array}{l}\text { Pemenuhan bahan } \\
\text { baku oleh supplier }\end{array}$ & $\%$ \\
\hline & \multirow{2}{*}{$\begin{array}{l}\text { Respo- } \\
\text { nsive- } \\
\text { ness }\end{array}$} & $\begin{array}{l}\text { Supplier mengirim } \\
\text { bahan baku tepat } \\
\text { waktu }\end{array}$ & $\%$ \\
\hline & & $\begin{array}{l}\text { Kecekatan supplier } \\
\text { dalam melayani } \\
\text { pesanan }\end{array}$ & Hari \\
\hline & $\begin{array}{l}\text { Flexi- } \\
\text { bility }\end{array}$ & $\begin{array}{l}\text { Fleksibilitas } \\
\text { supplier dalam } \\
\text { perubahan waktu } \\
\text { pengiriman bahan } \\
\text { baku }\end{array}$ & $\%$ \\
\hline & Asset & $\begin{array}{l}\text { Waktu siklus } \\
\text { pembayaran }\end{array}$ & Hari \\
\hline \multirow{4}{*}{ Make } & \multirow[b]{2}{*}{$\begin{array}{l}\text { Relia- } \\
\text { bility }\end{array}$} & $\begin{array}{l}\text { Jumlah produk yang } \\
\text { cacat }\end{array}$ & $\%$ \\
\hline & & $\begin{array}{l}\text { Efisiensi alat dan } \\
\text { mesin dalam } \\
\text { pembuatan produk }\end{array}$ & Jam \\
\hline & $\begin{array}{l}\text { Respo- } \\
\text { nsive- } \\
\text { ness }\end{array}$ & $\begin{array}{l}\text { Waktu pembuatan } \\
\text { produk }\end{array}$ & Hari \\
\hline & $\begin{array}{l}\text { Flexi- } \\
\text { bility }\end{array}$ & $\begin{array}{l}\text { Fleksibilitas dalam } \\
\text { jumlah pembuatan } \\
\text { produk }\end{array}$ & $\%$ \\
\hline
\end{tabular}




\begin{tabular}{|l|l|l|c|}
\hline Cost & Biaya Produksi & $\mathrm{Rp.}$ \\
\cline { 2 - 4 } & Asset & $\begin{array}{l}\text { Lama rata - rata } \\
\text { masa pakai mesin } \\
\text { las }\end{array}$ & $\begin{array}{c}\text { Tahu } \\
\mathrm{n}\end{array}$ \\
\hline
\end{tabular}

\begin{tabular}{|c|c|c|c|}
\hline $\begin{array}{l}\text { Proses } \\
\text { Inti }\end{array}$ & $\begin{array}{l}\text { Dim- } \\
\text { ensi }\end{array}$ & KPI & $\begin{array}{c}\text { Satu- } \\
\text { an }\end{array}$ \\
\hline \multirow{5}{*}{ Deliver } & \multirow{2}{*}{$\begin{array}{l}\text { Relia- } \\
\text { bility }\end{array}$} & $\begin{array}{l}\text { Kecepatan dalam } \\
\text { pengiriman produk }\end{array}$ & Hari \\
\hline & & $\begin{array}{l}\text { Perfect Order } \\
\text { Fulfillment }\end{array}$ & $\%$ \\
\hline & $\begin{array}{l}\text { Respo- } \\
\text { nsive- } \\
\text { ness }\end{array}$ & $\begin{array}{l}\text { Waktu siklus } \\
\text { pemenuhan pesanan }\end{array}$ & Hari \\
\hline & $\begin{array}{l}\text { Flexibi } \\
\text { lity }\end{array}$ & $\begin{array}{l}\text { Fleksibilitas dalam } \\
\text { pengiriman jumlah } \\
\text { produk }\end{array}$ & $\%$ \\
\hline & Cost & $\begin{array}{l}\text { Biaya pengiriman } \\
\text { produk }\end{array}$ & Rp. \\
\hline & $\begin{array}{l}\text { Relia- } \\
\text { bility }\end{array}$ & $\begin{array}{l}\text { Tingkat penolakan } \\
\text { bahan baku }\end{array}$ & $\%$ \\
\hline Return & $\begin{array}{l}\text { Respo- } \\
\text { nsive- } \\
\text { ness }\end{array}$ & $\begin{array}{l}\text { Waktu yang } \\
\text { dibutuhkan supplier } \\
\text { untuk mengganti } \\
\text { bahan baku yang } \\
\text { rusak }\end{array}$ & Hari \\
\hline
\end{tabular}

\subsection{Data Project Perusahaan}

Berikut merupakan project-project yang ditangani oleh PT. Ravana Jaya pada tahun 2018 yang akan dilakukan pengukuran kinerja supply chain pada tiap projectnya

Tabel 5. Project PT. Ravana Jaya tahun 2018

\begin{tabular}{|c|c|c|c|c|c|}
\hline No & $\begin{array}{c}\text { Nama } \\
\text { Project }\end{array}$ & Klient & Periode & $\begin{array}{c}\text { Volume } \\
(\text { Kg) }\end{array}$ & $\begin{array}{c}\text { Nilai } \\
\text { Kontrak } \\
\text { (Rp.) }\end{array}$ \\
\hline 1 & $\begin{array}{c}\text { Pengolahan } \\
\text { Kelapa } \\
\text { Sawit }\end{array}$ & $\begin{array}{c}\text { PT } \\
\text { Pilaren }\end{array}$ & $\begin{array}{c}\text { Januari - } \\
\text { Maret }\end{array}$ & 39002 & $858,050,000$ \\
\hline 2 & $\begin{array}{c}\text { Pagar } \\
\text { Pabrik }\end{array}$ & $\begin{array}{c}\text { PT } \\
\text { Swadaya }\end{array}$ & $\begin{array}{c}\text { April - } \\
\text { Juli }\end{array}$ & 55000 & $1,100,000,000$ \\
\hline 3 & Jembatan & PT KMS & $\begin{array}{c}\text { Agustus - } \\
\text { September }\end{array}$ & 65455 & $1,440,000,000$ \\
\hline 4 & $\begin{array}{c}\text { Rumah } \\
\text { Pompa }\end{array}$ & Pilmar & $\begin{array}{c}\text { September } \\
\text { - Oktober }\end{array}$ & 17091 & $376,000,000$ \\
\hline
\end{tabular}

\subsection{Hirarki SCOR}

Hirarki proses inti, dimensi, dan KPI ditunjukkan pada gambar 3.Hirarki ini akan berpengaruh pada perhitungan bobot tiap KPI. Bobot pada setiap level merupakan bagian dari bobot pada level selanjutnya.

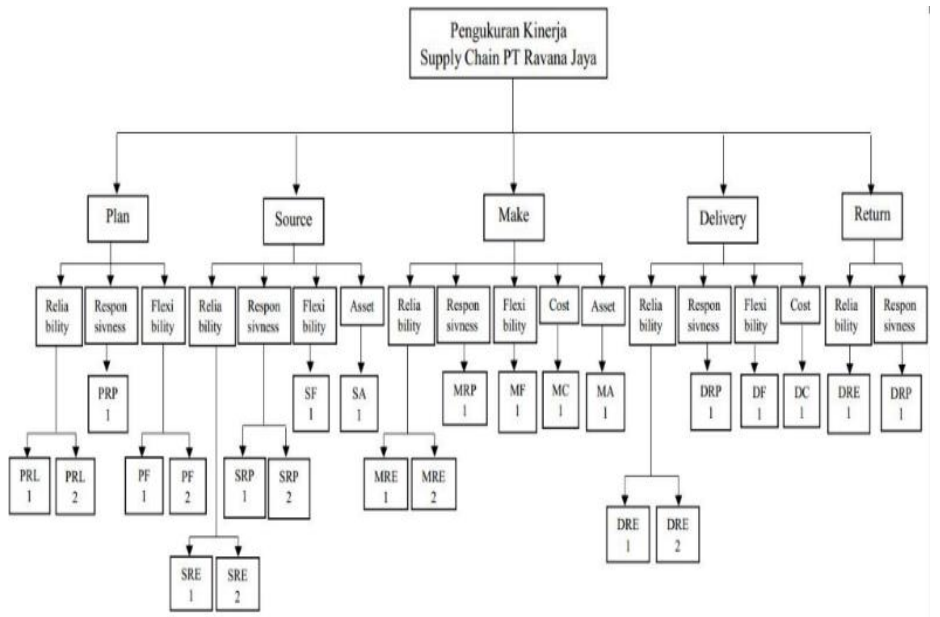

Gambar 3. Hierarki SCOR Pengukuran kinerja supplychain PT. Ravana Jaya

\subsection{Perhitungan Nilai Performansi KPI}

Hasil pengukuran total kinerja supply chain pada PT. Ravana Jaya ditunjukkan pada tabel 5. Total nilai kinerja merupakan hasil perkalian antara masingmasing bobot dengan skor.

\begin{tabular}{|c|c|c|c|c|c|c|c|c|c|}
\hline \multirow{3}{*}{ KPI } & \multirow{2}{*}{\multicolumn{4}{|c|}{$\begin{array}{c}\text { Nilai Normalisasi } \\
2018\end{array}$}} & \multirow{3}{*}{$\begin{array}{l}\text { Bo } \\
\text { bot }\end{array}$} & \multirow{2}{*}{\multicolumn{4}{|c|}{$\begin{array}{c}\begin{array}{c}\text { Indeks Kinerja } \\
\text { SCOR }\end{array} \\
\mathbf{2 0 1 8} \\
\end{array}$}} \\
\hline & & & & & & & & & \\
\hline & 1 & 2 & 3 & 4 & & 1 & 2 & 3 & 4 \\
\hline $\begin{array}{l}\text { Akurasi } \\
\text { perkiraan } \\
\text { jumlah bahan } \\
\text { baku }\end{array}$ & 100 & 33,34 & 100 & 100 & 0,038 & 3,8 & 1,27 & 3,8 & 3,8 \\
\hline $\begin{array}{l}\text { Kehandalan } \\
\text { karyawan }\end{array}$ & 60 & 60 & 100 & 100 & 0,087 & 5,22 & 5,22 & 8,7 & 8,7 \\
\hline $\begin{array}{l}\text { Kecepatan } \\
\text { dalam } \\
\text { menanggapi } \\
\text { perubahan } \\
\text { permintaan } \\
\text { jumlah bahan } \\
\text { baku }\end{array}$ & 30,77 & 15,38 & 0 & 84,61 & 0,103 & 3,17 & 1,58 & 0 & 8,71 \\
\hline $\begin{array}{l}\text { Fleksibilitas } \\
\text { penjadwalan } \\
\text { Produksi }\end{array}$ & 100 & 100 & 28,57 & 100 & 0,042 & 4,2 & 4,2 & 1,2 & 4,2 \\
\hline $\begin{array}{l}\text { Fleksibilitas } \\
\text { dalam } \\
\text { memenuhi } \\
\text { jumlah } \\
\text { permintaan } \\
\text { pelanggan }\end{array}$ & 100 & 100 & 100 & 100 & 0,016 & 1,6 & 1,6 & 1,6 & 1,6 \\
\hline $\begin{array}{l}\text { Persentase } \\
\text { kecacatan } \\
\text { bahan baku }\end{array}$ & 53,53 & 77,28 & 100 & 48,94 & 0,004 & 0,21 & 0,31 & 0,4 & 0,20 \\
\hline
\end{tabular}




\begin{tabular}{|l|c|c|c|c|c|c|c|c|c|}
\hline $\begin{array}{l}\text { Pemenuhan } \\
\text { bahan baku } \\
\text { oleh supplier }\end{array}$ & 63,40 & 28,79 & 64,34 & 61,75 & 0,009 & 0,57 & 0,26 & 0,58 & 0,56 \\
\hline $\begin{array}{l}\text { Supplier } \\
\text { mengirim } \\
\text { bahan baku } \\
\text { tepat waktu }\end{array}$ & 33,33 & 11,11 & 20 & 11,11 & 0,021 & 0,7 & 0,23 & 0,42 & 0,23 \\
\hline
\end{tabular}

Berdasarkan sistem monitoring ndikator performansi, dari perhitungan hilai performansi kinerja yang telah dilakukan dapat diketahui bahwa di

\begin{tabular}{|c|c|c|c|c|c|c|c|c|c|}
\hline \multirow{3}{*}{ Kpi } & \multicolumn{4}{|c|}{ Nilai Normalisasi } & \multirow{3}{*}{$\begin{array}{c}\text { Bo } \\
\text { bo } \\
\mathbf{t}\end{array}$} & \multirow{2}{*}{\multicolumn{4}{|c|}{$\begin{array}{c}\text { Indeks Kinerja Scor } \\
2018\end{array}$}} \\
\hline & \multicolumn{4}{|c|}{2018} & & & & & \\
\hline & 1 & 2 & 3 & 4 & & 1 & 2 & 3 & 4 \\
\hline $\begin{array}{l}\text { Kecekatan } \\
\text { supplier dalam } \\
\text { melayani } \\
\text { pesanan } \\
\end{array}$ & 100 & 0 & 100 & 100 & 0,013 & 1,3 & 0 & 1,3 & 1,3 \\
\hline $\begin{array}{l}\text { Fleksibilitas } \\
\text { supplier dalam } \\
\text { perubahan } \\
\text { waktu } \\
\text { pengiriman } \\
\text { bahan baku } \\
\end{array}$ & 100 & 100 & 0 & 100 & 0,021 & 2,1 & 2,1 & 0 & 2,1 \\
\hline $\begin{array}{l}\text { Waktu siklus } \\
\text { pembayaran }\end{array}$ & 52,63 & 100 & 0 & 52,63 & 0,051 & 2,68 & 5,1 & 0 & 2,68 \\
\hline $\begin{array}{l}\text { Jumlah produk } \\
\text { yang cacat }\end{array}$ & 83,18 & 81,09 & 89,95 & 42,25 & 0,079 & 6,57 & 6,41 & 7,11 & 3,34 \\
\hline $\begin{array}{l}\text { Efisiensi alat } \\
\text { dan mesin } \\
\text { dalam } \\
\text { pembuatan } \\
\text { produk }\end{array}$ & 100 & 100 & 100 & 0 & 0,039 & 3,9 & 3,9 & 3,9 & 0 \\
\hline $\begin{array}{l}\text { Waktu } \\
\text { pembuatan } \\
\text { produk }\end{array}$ & 0 & 20,83 & 41,67 & 100 & 0,071 & 0 & 1,48 & 2,96 & 7,1 \\
\hline $\begin{array}{l}\text { Fleksibilitas } \\
\text { dalam jumlah } \\
\text { pembuatan } \\
\text { produk }\end{array}$ & 100 & 33,34 & 0 & 100 & 0,055 & 5,5 & 1,83 & 0 & 5,5 \\
\hline Biaya Produksi & 50,11 & 100 & 55,06 & 64,94 & 0,039 & 1,95 & 3,9 & 2,15 & \\
\hline $\begin{array}{l}\text { Lama rata - rata } \\
\text { masa pakai } \\
\text { mesin las }\end{array}$ & 100 & 100 & 100 & 100 & 0,025 & 2,5 & 2,5 & 2,5 & 2,5 \\
\hline $\begin{array}{l}\text { Kecepatan } \\
\text { dalam } \\
\text { pengiriman } \\
\text { produk }\end{array}$ & 100 & 100 & 100 & 100 & 0,012 & 1,2 & 1,2 & 1,2 & 1,2 \\
\hline $\begin{array}{l}\text { Perfect Order } \\
\text { Fulfillment }\end{array}$ & 100 & 50 & 50 & 0 & 0,038 & 3,8 & 1,9 & 1,9 & 0 \\
\hline $\begin{array}{l}\text { Waktu siklus } \\
\text { pemenuhan } \\
\text { pesanan }\end{array}$ & 0 & 26,67 & 43,33 & 100 & 0,068 & 0 & 1,81 & 2,95 & 6,8 \\
\hline $\begin{array}{l}\text { Fleksibilitas } \\
\text { dalam } \\
\text { pengiriman } \\
\text { jumlah produk }\end{array}$ & 100 & 100 & 0 & 100 & 0,037 & 3,7 & 3,7 & 0 & 3,7 \\
\hline $\begin{array}{l}\text { Biaya } \\
\text { pengiriman } \\
\text { produk }\end{array}$ & 66,67 & 33,33 & 33,33 & 0 & 0,028 & 1,87 & 0,93 & 0,93 & 0 \\
\hline $\begin{array}{l}\text { Tingkat } \\
\text { penolakan } \\
\text { bahan baku }\end{array}$ & 53,53 & 77,28 & 100 & 48,94 & 0,032 & 1,71 & 2,47 & 3,2 & 1,57 \\
\hline $\begin{array}{l}\text { Waktu yang } \\
\text { dibutuhkan } \\
\text { supplier untuk } \\
\text { mengganti } \\
\text { bahan baku } \\
\text { yang rusak }\end{array}$ & 50 & 100 & 100 & 100 & 0,073 & 3,65 & 7,3 & 7,3 & 7,3 \\
\hline & JUN & LAH & & & & 61,9 & 61,21 & 54,09 & 75,62 \\
\hline
\end{tabular}
tahun 2018 pada project 1 nilai kinerja supply chain PT. Ravana Jaya adalah 61,91 (average), project 2 sebesar 61,21 (average), project 3 sebesar 54,09 (average), dan pada project 4 sebesar 75,62 (good).

\section{KESIMPULAN DAN SARAN}

\subsection{Kesimpulan}

Dari penelitian yang telah dilakukan, dapat disimpulkan bahwa :

1. Terdapat 24 KPI yang digunakan dalam pengukuran kinerja supply chain di PT. Ravana Jaya. 24 KPI ini terdiri dari 5 KPI dari proses plan, 6 KPI dari proses source, 6 KPI dari proses make, $5 \mathrm{KPI}$ dari proses deliver, dan 2 KPI dari proses return.

2. Nilai kinerja supply chain PT. Ravana Jaya apabila diukur dengan menggunakan Supply chain Operation Reference di tahun 2018 pada project 1 nilai kinerja spply chain PT. Ravana Jaya adalah 61,91 (average), project 2 sebesar 61,21 (average), project 3 sebesar 54,09 (average), dan pada project 4 sebesar 75,62 (good).

\subsection{Saran}

Dari penelitian yang dilakukan, maka ada beberapa saran yang perlu diperhatikan

1. Pengukuran kinerja ini berguna bagi perusahaan untuk mengevaluasi kinerja tiap indicator kinerja supply chain management perusahaan, sehingga perusahaan dapat melakukan perbaikan secara terus-menerus. 
2. Perbaikan dapat dilakukan terhadap indicator yang memiliki kinerja rendah sehingga tingkat pencapaian terhadaptarget yang telah ditetapkan perusahaan dapat ditingkatkan lagi. Selain itu, perusahaan sebaiknya tetap memepertahankan KPI yang memiliki kinerja baik.

3. Agar perancangan pengukuran kinerja dengn menggunakan Supply Chain Operation Reference (SCOR) bisa diterapkan dengan baik dan efektif, maka perlu kemauan, kerja keras, dan dukungan moril maupun materil yang memadai dari pimpinan dan segenap karyawan.

\section{DAFTAR PUSTAKA}

Parmenter,

D.

(2010).

Mengembangkan,

Mengimplementasikan dan

Menggunakan Key

Performance Indicators.

(Hauriyah, Trans.). Jakarta: PPM

Pujawan, I., \& Mahendrawathi, E.R.
Supply
Chain
Management (2nd ed.).
Surabaya: Guna Widya.

Rakhman, dkk. (2018). Kinerja Manajemen Rantai Pasok Dengan Menggunakan Pendekatan Metode Supply Chain Operation Reference (SCOR). Jurnal Aplikasi Manajemen dan Bisnis, 4(1), 106-118.

Saaty, Thomas L. (1993). Pengambilan Keputusan Bagi Para Pemimpin. Jakarta: PT. Pustaka Binaman Pressindo.
Soemohadiwidjojo, A. T. (2015). Panduan Praktis Menyusun KPI. Jakarta : Raih Asa Sukses.

Trasewicz, Rafal. (2016). Integrated Approach to Supply Chain Performance Meaurement Result of Study on Polish Market. Transportation Reseach Prosedia, 14, 143-1442.

Vanany, dkk. (2005). Design of Supply Chain Performance Measurement System for Lamp Industry. Bali: $1^{\text {st }}$ International Conference on Operations and Supply Chain Management.

Vanany, Iwan. (2009). Performance Measurement: Model \& Aplikasi. (Cetakan ke-2). Surabaya: ITSPress.

Wigati, dkk. (2017). Pengukuran Kinerja Supply Chain Dengan Menggunakan Supply Chain Operation Reference (SCOR) Berbasis Analytical Hierarchy Process (AHP). Journal Industrial Servicess, 3(1a), 4652 